\title{
RESSIGNIFICANDO O FRACASSO ESCOLAR: DA DIFICULDADE DE APRENDIZAGEM À INJUSTIÇA COGNITIVA - ENSINAR E APRENDER COM ARTES
}

\author{
RENUNCIA AL FRACASO ESCOLAR: DE LA DIFICULTAD DE APRENDIZAJE A LA INJUNTICIA \\ COGNITIVA - ENSEÑAR Y APRENDER COM LAS ARTES
}

D https://orcid.org/0000-ooo1-6943-4905 Carmen Lúcia Vidal Pérez ${ }^{\mathrm{A}}$ https://orcid.org/0000-0001-9974-1965 Nathália Fonseca da Silva Barboza ${ }^{B}$

(D) https://orcid.org/0000-0002-7553-4934 Vânia Baptista Garcia ${ }^{\mathrm{C}}$

\footnotetext{
${ }^{\text {A }}$ Faculdade de Educação da Universidade Federal Fluminense (UFF), Niterói, RJ, Brasil

${ }^{\text {B }}$ Faculdade de Educação da Universidade Federal Fluminense (UFF), Niterói, RJ, Brasil

${ }^{\mathrm{C}}$ Faculdade de Educação da Universidade Federal Fluminense (UFF), Niterói, RJ, Brasil
}

Recebido em: 12022020 | Aceito em: 16072020 Correspondência: Carmem (clvperez@gmail.com ); Nathália (nathaliafonseca@id.uff.br ) Vania (vaniagarcia@id.uff.br )

\section{Resumo}

Nosso objetivo é investigar a formulação de outras possibilidades para a ação educativa a partir da concepção de Injustiças Cognitivas. A pesquisa se desenvolve num ambulatório de Neuropsiquiatria Infantil, que atende crianças e adolescentes, das classes populares. O que sabe quem não sabe? Tal pergunta nos lança no contra movimento de aprender com as crianças como ensiná-las. Ao narrar as experiências vividas com um grupo de 16 crianças e adolescentes, buscamos refletir sobre suas conquistas. Para nós a arte é um dispositivo de inter(in)venção, pois entendemos que a expressão artística revela sentimentos ocultos, porém, muito importantes que auxiliam o mediador (professores e terapeutas) a melhor atender às necessidades do educando no período escolar.

Palavras-chave: Injustiça Cognitiva; Arte; Mediação.

\section{Resumen}

Nuestro objetivo es investigar la formulación de otras posibilidades de acción educativa basadas en el concepto de injusticias cognitivas. La investigación se lleva a cabo en una clínica ambulatoria de Neuropsiquiatría Infantil, que atiende a niños y adolescentes, de las clases bajas. ¿Qué sabes quién no? Tal pregunta nos lanza al contramovimiento de aprender de los niños cómo enseñarles. Al narrar las experiencias vividas con un grupo de 16 niños y adolescentes, buscamos reflexionar sobre sus logros. Para nosotros, el arte es un dispositivo de intervención, ya que entendemos que la expresión artística revela sentimientos ocultos, sin embargo, muy importante que puede ayudar al mediador (maestros y terapeutas) a satisfacer mejor las necesidades del estudiante durante el período escolar.

Palabras clave: Injusticia cognitiva;Arte; Mediación. 


\section{Iniciando a Conversa}

Questões envolvendo a aprendizagem, historicamente, imputam ao sujeito a culpa por tudo aquilo que, durante o processo, não segue as etapas normatizadas socialmente no espaço-tempo do cotidiano escolar. Observamos o movimento de caça aos "culpados" que se sobrepõe a busca pela identificação das especificidades, que influencia o processo de aprendizado dos aprendentes. Cada criança como sujeito do conhecimento tem tempo e forma singular aprender - e que no caso dos "portadores de deficiência" não se enquadra na expectativa normativa da sociedade em relação à aprendizagem. A dicotomia entre os tempos do ensinar e do aprender é vista como um problema do aprendente, cuja solução (apressada) esperada pela escola é o laudo e a consequente medicalização, que inscrevem a criança aprendente na esfera do fracasso escolar, fenômeno complexo que se articula a problemáticas sociais mais amplas e que na escola se configura como o que vimos chamando, apoiadas em Skliar (2003), de uma pedagogia hostil.

A padronização do processo ensino-aprendizagem coloca a parte o sujeito com "deficiência", nega (e muitas vezes impedem) as interações com o outro em sua forma singular de relacionar-se com o mundo. A ação escolar de um modo geral traduz uma pedagogia pautada numa perspectiva epistêmica que valoriza o ensino - "só se aprende aquilo que é ensinado"- em detrimento dos complexos processos de aprendizagem e as diferentes nuances do conhecimento. Ou seja, quem não aprende aquilo que lhe ensinam, é categorizado como portador de dificuldade / distúrbio de aprendizado e incluído na esfera do fracasso escolar. Nesse sentido, como já assinalamos a pesquisai, que desenvolvemos com crianças (e adolescentes) de classes populares "portadores de deficiência", busca investigar a formulação de novas possibilidades para a ação educativa da escola a partir da revisão-ampliação do conceito de cognição, articulando-o a uma perspectiva político-epistemológica fundada na concepção de "Injustiças Cognitivas". A substituição do conceito de dificuldade de aprendizagem pelo conceito de Injustiça Cognitiva, mais do que uma mudança paradigmática é uma opção político-epistemológica voltada para a garantia do direito das crianças das classes populares (deficientes ou não) de aprender na escola (PÉREZ, 2019, p.12).

Tomamos sempre o cuidado em não falar sobre, ou pelas crianças e adolescentes e suas relações com a escola, seja a partir das nossas observações, seja em nossas conversas e encontros com as próprias crianças, suas famílias, suas professoras e outros profissionais envolvidos. Tal postura se ancora numa relação de alteridade que reconhece (e respeita) a necessidade do outro falar por si mesmo, sobre si mesmo, processo de assunção de si, mediatizado pelo coletivo, que no dizer de Freire (1996) é uma das mais importantes tarefas da prática educativo-crítica, pois busca:

[...] propiciar as condições em que os educandos em relação uns com os outros e todos com o professor ou a professora ensaiam a experiência profunda de 
assumir-se. Assumir-se como ser social e histórico, como ser pensante, comunicante, transformador, criador, realizador de sonhos, capaz de ter raiva porque capaz de amar. Assumir-se como sujeito porque capaz de e conhecerse como objeto. A assunção de nós mesmos não significa a exclusão dos outros. É a "outredade" do "não eu", ou do tu, que me faz assumir a radicalidade de meu eu. (FREIRE, 1996, p.23-24).

Ao focar a amorosidade (no sentido freireano do termo) como princípio de uma prática educativo-crítica fundado na outretade e, em diálogo com o princípio de alteridade defendido por Maturana (1998), cujo fundamento é a prática amorosa de ouvir o outro reconhecendo-o como legítimo outro, ou seja, o amor como o domínio de comportamentos relacionais "através dos quais um outro ser surge como um legítimo outro na coexistência com alguém"(MATURANA,1998,p.195); buscamos na pesquisa e em nossas inter(in)venções ${ }^{\mathrm{ii}}$ pedagógicas com as crianças e adolescentes, conhecer e potencializar os saberes da experiência feitos (FREIRE, 1996) como atos de conhecimento. A pergunta “o que sabe quem não sabe", nos inquieta e nos lança à busca. Desafio que exige a ruptura das "certezas estabelecidas". Desconfiamos dos discursos hegemônicos que aprisionam o outro, o diferente, no lugar da falta, do não saber, da doença. O olhar da cultura (escolar) dominante é sempre de subalternização do outro - o outro que pertencente a uma cultura diferente é visto como um "ninguém" que precisa ser ensinado e civilizado. Na escola o diferente é o outro, o que altera a (falsa) harmonia positivista fundada na homogeneidade. Nesta perspectiva, o outro - o ninguém, o menor - é visto em sua diferença como "portador de um problema", "de um distúrbio", "de uma incapacidade". Na escola a diferença é tratada como doença e o diferente como doente.

A escola como campo de pesquisa, nos conduziu a outras reflexões que demandaram a reconfiguração do desenho inicial da investigação. Estudar o fracasso escolar a partir do conceito de Injustiças Cognitivas implica também em sair da escola, pois embora seja um fenômeno marcadamente escolar, entendemos que sua gênese não está na escola e, que essa se reinventada em sua base epistêmica, metodológica e pedagógica, pode deixar de ser um campo fértil de Injustiça Cognitiva para se constituir num espaço de configuração de Justiça (Cognitiva), Social. Para superar a estereotipia e combater preconceitos é necessário compreender os processos sociais, de educação e saúde envolvidos nas tentativas de normatização e inserção social dessas "pessoas tão diferentes".

Em busca da superação de discursos (e conceitos), redirecionamos nossas ações de pesquisa para o local onde as crianças e adolescentes são encaminhadas. Sem abandonar a escola, buscamos observar e participar do processo de atendimento a crianças, que segundo a escola apresentam problemas de aprendizagem. O campo de pesquisa escolhido foi o Ambulatório Comunitário de Neuropsiquiatria Infantil (GEAL) coordenado pelo Prof. Dr. Jairo Werner (Professor Titular da Faculdade de Medicina), um espaço multidisciplinar que atua na perspectiva da Saúde Mental Inovadora, em que as visões mecanicistas $^{\text {iii }}$ e organicistas ${ }^{\text {iv }}$ são superadas pela visão histórico-cultural ${ }^{v}$. A perspectiva de trabalho do GEAL é buscar as potencialidades dessas crianças e adolescentes onde a escola e a sociedade enxergam 
apenas impotência, ou seja, não se pautar no que está posto por diagnóstico e/ou laudo, não medicalizar de forma exacerbada, mas sim, apostar em atendimentos terapêuticos e pedagógicos, que potencializem a aprendizagem e a autoestima das "pessoas com deficiência". O atendimento é voltado a crianças e adolescentes com a demanda explicita de alterações comportamentais, encaminhadas por escolas, SUS, Conselho Tutelar e Ministério Público.

A primeira fase da pesquisa foi dividida em duas etapas. A primeira etapa girou em torno da coleta de dados com o objetivo de identificar os motivos dos encaminhamentos ${ }^{\mathrm{vi}}$, e de onde partiam. Trabalhamos com um grupo com 16 crianças (e adolescentes) atendidas semanalmente no GEAL. Como resultado deste levantamento, identificamos 46 queixas iniciais (cada criança /adolescente tem mais de uma queixa inicial, muitas vezes elas são recorrentes e coincidem com as de outras crianças/adolescentes) que agrupadas nos apontou 18 motivos comuns aos encaminhamentos e, constamos que a instituição escolar realizou o maior número de encaminhamentos para o GEAL. A fim de observar a coerência entre os motivos dos encaminhamentos (queixa inicial) e o comportamento das crianças e adolescentes no sentido pedagógico, passamos a segunda etapa da primeira fase, a Anamnese Pedagógica. Do total de 16 encaminhamentos feitos pela escola (sendo todos com, ao menos, um motivo de encaminhamento/queixa inicial de dificuldade de aprendizagem), somente quatro demonstraram coerência em relação ao aspecto pedagógico. A segunda etapa foi desenvolver um trabalho (pedagógico) de leitura e escrita a partir das demandas e interesses dos adolescentes, é nesse momento que optamos pela Arte como dispositivo de experimentação pedagógica.

\section{Educação e arte}

Anualmente o GEAL realiza uma festa de encerramento das atividades e para este ano a proposta era de uma Feira Medieval. Cada grupo atendido desenvolveria uma atividade para ser apresentada, o grupo dos adolescentes, que acompanhávamos, demonstrou interesse pelas histórias que envolviam batalhas, a partir daí começamos a desenvolver a experimentação pedagógico. A primeira etapa foi contextualizar a época da Idade Média. Pedimos que cada um pesquisasse sobre a Idade Média e o que mais lhes interessava naquele período. Em momento algum duvidamos de sua capacidade e interesse, para realizar a pesquisa solicitada, e solicitamos o apoio dos responsáveis para ajudá-los na tarefa, como forma de se envolver, apoiar, acompanhar e compartilhar o processo de construção de conhecimentos de seus filhos. A partir dos "dados" da pesquisa (vestuário, armas, comidas, vida social, política, artes, músicas) elaboramos coletivamente o projeto de encenar uma peça teatral sobre a Idade Média. É importante destacar que algumas pesquisas foram entregues a escritas à mão com desenhos de armaduras, armas; outras vieram com impressões coloridas com vestuários femininos e 
masculinos ricos em seus detalhes. $\mathrm{O}$ resultado nos surpreendeu e, animadas com o envolvimento de todos deslumbramos a possibilidade de realizar o projeto de uma "Peça Medieval" (nome escolhido coletivamente pelo grupo), o que exigiu maior compromisso de cada um. Iniciamos a produção da "peça medieval" com a construção do texto coletivo (enredo); nem todos escreveram nesse primeiro dia, mas ficaram atentos às conversas dos colegas, participando de alguma forma. Alguns declararam dificuldade para atuar, e outros mais animados, já no primeiro dia escreveram quatro páginas de uma história fantástica, rica em detalhes.

No encontro seguinte, continuamos a produção de texto e definimos a escolha dos personagens que cada um iria interpretar. Estavam todos animadíssimos com a possibilidade de interpretar um personagem com as características que eles mesmos definiram.

É o meu bom-senso, em primeiro lugar, o que me deixa suspeitoso, no mínimo, de que não é possível à escola, se, na verdade, engajada na formação, de educandos e educadores, alhearem-se das condições sociais culturais, econômicas de seus alunos, de suas famílias, de seus vizinhos. Não é possível respeito aos educandos, à sua dignidade, a seu ser formando-se, à sua identidade fazendo-se, se não se levam em consideração às condições em que eles vêm existindo, se não se reconhece a importância dos "conhecimentos de experiência feitos" com que chegam à escola. O respeito devido à dignidade do educando não me permite subestimar, pior ainda, zombar do saber que ele traz consigo para a escola. (FREIRE, 1996, p.62).

Para que não houvesse muitas faltas nos encontros seguintes, fizemos uma reunião com as mães e sugerimos que elas participassem da Feira Medieval com uma barraca de comida e artesanatos, para que estivessem mais próximas de seus filhos e filhas acompanhando-os/as na peça teatral. Nesse momento conversamos sobre suas dificuldades com seus filhos e filhas no dia a dia, na escola, sobre o comportamento deles em casa e, algumas dúvidas sobre sua participação: será que conseguiriam subir ao palco para realizar tal feito diante de uma plateia? Afirmamos diante daquelas mães nossa crença no potencial de seus filhos/as e ressaltamos os da importância do respeito, do incentivo e de seu apoio emocional ao filho/a para o sucesso do projeto, para tanto, a assiduidade aos encontros se fazia essencial e sua ajuda e compreensão eram fundamentais. 
59. Uma parceria cooperativa e de apoio entre administradores escolares, professores e pais deveria ser desenvolvida e pais deveriam ser considerados enquanto parceiros ativos nos processos de tomada de decisão. Pais deveriam ser encorajados a participar em atividades educacionais em casa e na escola (aonde eles poderiam observar técnicas efetivas e aprender como organizar atividades extracurriculares), bem como na supervisão e apoio à aprendizagem de suas crianças. (Declaração de Salamanca -1996).

Pensando numa educação inclusiva de fato, observamos, respeitamos e estimulamos a cada um/a do grupo a enfrentar/superar suas dificuldades, anseios e receios. A instabilidade emocional marcava cada encontro com o grupo, cada etapa da produção e cada ensaio. Um encontro não era igual ao outro, ora estavam animados, ora medrosos, oscilavam frequentemente entre a euforia e a alegria, o desânimo e a insegurança diante da pressão a que se julgavam submetidos. Muitas conversas individuais, olho no olho, muito carinho e abraços, muitas emoções colocadas nas conversas, firmando uma relação de confiança que ao longo do projeto envolveu todo grupo. Com relatos de exclusão e bullying nas escolas, muitas vezes por parte de colegas, professores e até mesmo familiares em casa, vimos o quanto o estigma marca as pessoas que fazem acompanhamento psiquiátrico regular, e a falta de empatia da sociedade com a sua luta diária para se manter emocionalmente equilibrado diante de tantas adversidades e incompreensões.

Figura 1: Colagem: Feira Medieval

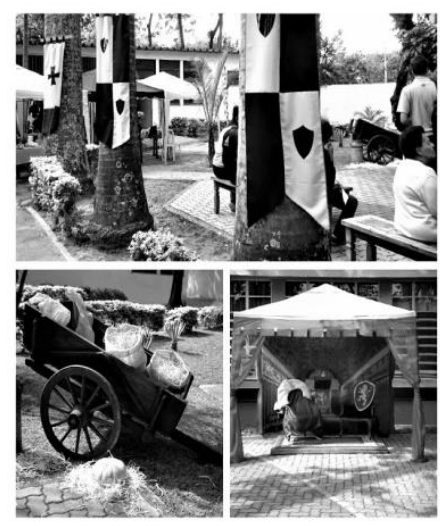

Fonte: Acervo da pesquisa 
A ideia da peça teatral partiu da necessidade do reencontro dos talentos individuais de cada um. A autoestima das crianças e adolescentes estava baixa, como também as expectativas em relação a si mesmas. A relação entre eles, no grupo de conversa era amena, sem muita espontaneidade, pois muitos não queriam expor suas intimidades ou, aqueles que tomam remédios controlados ficavam apáticos nos encontros, e ainda tínhamos que lidar com uma rotina familiar comprometida pela não aceitação de suas patologias, e comportamentos agitados ou agressivos.

(...) só são sociais as relações que se fundam na aceitação do outro como um legítimo outro na convivência, e que tal aceitação é o que constitui uma conduta de respeito. Sem uma história de interações suficientemente recorrentes, envolventes e amplas, em que haja aceitação mútua num espaço aberto às coordenações de ações, não podemos esperar que surja a linguagem. Se não há interações na aceitação mútua, produz-se a separação ou a destruição. Em outras palavras, se há na história dos seres vivos algo que não pode surgir na competição, isso é a linguagem. (MATURANA, 1998, p.24).

Apesar de muita resistência inicial, em atuar no palco diante de uma plateia desconhecida, percebemos que queriam realizar algo importante, deixar sua marca. Após muita conversa e negociação com cada um individualmente, o interesse em participar do projeto aumentou significativamente e, envolveu a todos. Reafirmamos nossa aposta no potencial da arte: passaram a se expressar mais intensamente, e colocaram toda sua energia, ao manifestar sentimentos, muitas vezes repreendidos por tabus e preconceitos externos. Estar no palco representando, incorporando um personagem fictício, com liberdade de expressão emocional, potencializava cada um individualmente, a alegria e o prazer contagiou todo o grupo - até quem inicialmente havia se recusado a participar passou a ensaiar com o grupo e se firmou, ajudando os colegas até a apresentação final.

A oportunidade de mostrar seus talentos no projeto da "Peça Medieval" lhes permitiu, além de entrar em contato com situações novas de comprometimento real, realizar algo com a sua marca e, decidir a forma como queriam mostrar-se ao público - outro modo de se ver e ser visto. 


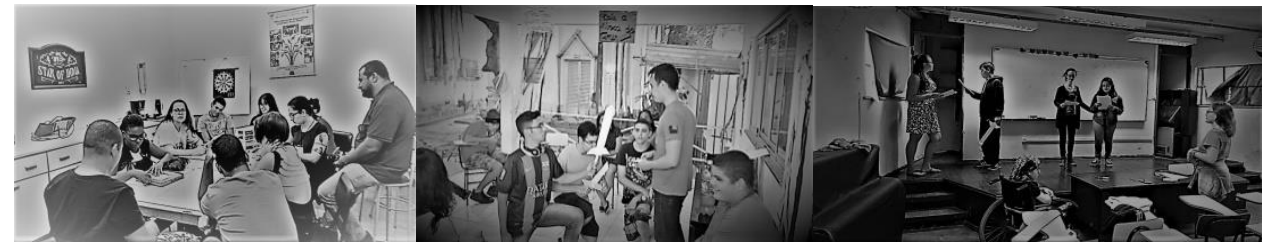

Fonte: acervo da pesquisa

Nesse período, mesmo com alguns momentos de crise ou desentendimento entre colegas do grupo do GEAL, as conversas objetivam deixar todos à vontade e mais seguros; a roda de conversas era momento colocando seus sentimentos e dificuldades. Muitos sentimentos de revolta, tristeza, desesperança, foram externalizados nos encontros de "ensaio", mas sempre ao final todos se animavam com a possibilidade de se mostrar de forma especial na peça. A gana de mostrar seus talentos para a família e o público, estava crescendo gradativamente, e a energia das reuniões mudou de forma positiva.

Pedimos a ajuda da psicóloga que integra o grupo, para que dirigisse os ensaios e concluísse o roteiro final. Já no primeiro ensaio todos os participantes foram especialmente profissionais de artes cênicas: interpretação, postura, impostação de voz, gestuais, presença de palco, etc. Ficamos muito emocionadas ao ver a dedicação de todos à peça. Houve duas desistências, por conta do estado psicológico e comportamental dos atendidos, pois haviam apresentado dificuldades anteriormente - um continuou assistindo aos ensaios, e o outro não compareceu mais aos encontros. Seus responsáveis informaram que seu estado emocional era inconstante e que estavam passando por dificuldades de relacionamento em casa e na escola. Com isso tivemos que preparar um plano B emergencial, para que não houvesse um desânimo e evasão por parte de outros. Assim, levamos já para os ensaios alguns adereços para que interagissem com o material necessário à composição de seus personagens. Com coroas, espadas, capas, os ensaios ficaram mais divertidos e a cada dia sua postura no palco ia ganhando novos contornos e mais substância.

\section{Racionalidade e emoções}

Gostaríamos de falar um pouco sobre a pressão que esses sujeitos - crianças e adolescentes - marginalizados (por suas condições psíquicas e psicológicas) sofrem cotidianamente. Quando pensamos nas condições dadas as crianças e jovens com "deficiência", 
ou que passam por situações traumáticas em suas vidas, ignorados em sua dor e, obrigados a atender exigências e normas que não têm condições de cumprir, vemos o quanto cruel pode ser o processo de normalização.

Nossa experiência no GEAL, convivendo com crianças e jovens talentosos que, ao mesmo tempo não acreditam em seus potenciais, tem nos permitido compreender como são enredados numa teia de impossibilidades, que cotidianamente os diminui e os oprime. Maturana (1998) fala sobre a competição negativa na educação, uma competição velada, não assumida e camuflada pelas questões sociais e econômicas. E, assim perguntamos: Como crianças e jovens com algum tipo de "deficiência" podem pensar em competir com outros jovens no mercado de trabalho, se nem as escolas eles podem frequentar? E, pior, quando matriculados nas escolas, são excluídos por diferentes motivos com a alegação de que as instituições de ensino não estão preparadas para recebê-los. Situações recorrentes e atuais nas escolas brasileiras, que marcam a hospitalidade hostil (SKLIAR, 2003) em relação as crianças e jovens com "deficiência" - que entram pela porta dos fundos com o estigma de incluídos, para serem excluídos no interior, no cotidiano da escola.

Nossa sociedade é excludente. Nossa escola acumula laudos médicos para justificar o injustificável, afinal, se nossa constituição afirma que a educação é para todos, e o Brasil assinou a Declaração de Salamanca, temos obrigação de acolher todos os educandos com suas necessidades educacionais. Parece utopia, porém não é impossível uma educação de qualidade para todos - uma educação verdadeiramente democrática, que respeite e assuma a diferença, sem discriminação social, cultural, religiosa, etc. Alguns professores valorizam as singularidades de seu educandos e, agem amorosamente. Amor, que como nos aponta Maturana (1998), com sua presença ou ausência rege as ações sociais, as interações e as emoções - pois são as emoções que resultam de nossas ações/interações sociais que nos potencializa, ou não, ou seja, são elas que nos alimentam e nos levam a seguir em frente ou não.

Os educandos com "deficiências" do GEAL foram conduzidos a um reencontro consigo mesmos, e quando perceberam seu potencial e seus talentos, viram que poderiam muito mais do que os laudos e estigmas que a sociedade lhes impõe proclamam e determinam. Esta foi uma descoberta importante e prazerosa que contagiou a todos, surpreendeu inclusive suas famílias, que passaram a vê-los com mais admiração e menos preconceito. Eles descobriram um potencial positivo dentro de si, uma capacidade de estar entre outras pessoas numa situação de igualdade e de potência, pois se sentiram fortalecidos ao pisar no palco e atuar, interpretando um texto criado por eles mesmos - texto que teve que ser cortado para que a peça não ficasse 
tão longa, porque não tínhamos tempo hábil para algo com quase uma hora de duração; o que foi explicado durante os ensaios, porque com tanta animação cada um foi acrescentando falas e ações no enredo.

Maturana (1998) nos fala sobre emoções negadas e suas consequências nas interações sociais, bem como do prejuízo que o excesso de valorização do racional, de atitudes racionais causa ao equilíbrio emocional do ser humano. Segundo o autor, nossa espécie evoluiu através das emoções, do cuidado uns com os outros, da necessidade do outro, da interação com o outro. Reduzir as emoções a algo animal, é negar que a maioria das decisões tomadas ao longo de nossas vidas são puramente emocionais e não racionais.

Buscando fortalecer o equilíbrio emocional dos educandos do GEAL, tentamos ao máximo promover um clima de harmonia nos encontros e ensaios: quando algo acontecia e os tiravam do foco da "peça", fazíamos pausas para conversas e eles falavam de seus sentimentos, depois voltavam a ensaiar.

Todos os conceitos e afirmações sobre os quais não temos refletido, e que aceitamos como se significassem algo simplesmente porque parece que todo o mundo os entende, são antolhos. Dizer que a razão caracteriza o humano é um antolho, porque nos deixa cegos frente à emoção, que fica desvalorizada como algo animal ou como algo que nega o racional. Quer dizer, ao nos declararmos seres racionais vivemos uma cultura que desvaloriza as emoções, e não vemos o entrelaçamento cotidiano entre razão e emoção, que constitui nosso viver humano, e não nos damos conta de que todo sistema racional tem um fundamento emocional. (MATURANA,1998, p.15).

A história final foi adaptada para melhor condução dos educandos, já que algumas falas eram muito longas e de difícil memorização. Deixá-los tranquilos e confiantes era imprescindível para que tudo andasse de acordo com o projeto da "Peça Medieval". Como não tínhamos verba para fazer frente à produção, figurino, acessórios e adereços cenográficos foram adaptados com a colaboração de todos, ou seja, cada um trouxe algo de casa que pudesse ser adaptado ao tema medieval. Tivemos que fazer adaptações com roupas próprias, confeccionar as espadas e os escudos usados na peça com papelão, compor bijuterias de acordo com as joias usadas pela realeza. Todos se encantaram com os acessórios! Perceberam que os acessórios complementavam a vestimenta medieval - adaptada com peças de roupa usadas no dia a dia do 
século XXI, o que possibilitou "entrar" nas personagens e perder o medo da apresentação em público.

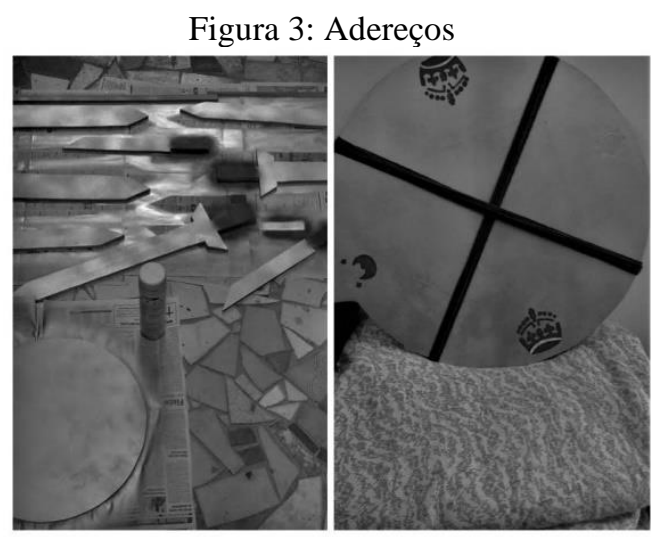

Fonte: Acervo da pesquisa

No dia da apresentação, todos estavam muito ansiosos, chegaram no horário marcado, queriam ver suas roupas e acessórios. Como num passe de mágica, todos fizeram sua parte sem esquecer as falas, sem ficarem nervosos e, arrancaram muitas risadas da plateia, e muitos aplausos durante a encenação. Seguramente um sucesso merecido por toda a dedicação e comprometimento desses jovens talentosos que mostraram suas particularidades teve coragem de se mostrar do seu jeito, e ao final da "Peça Medieval", cada um quis fazer seu agradecimento individual, sem ensaio, de improviso, emocionando todos da equipe do GEAL e o público.

Figura 4: Apresentação da Peça Medieval

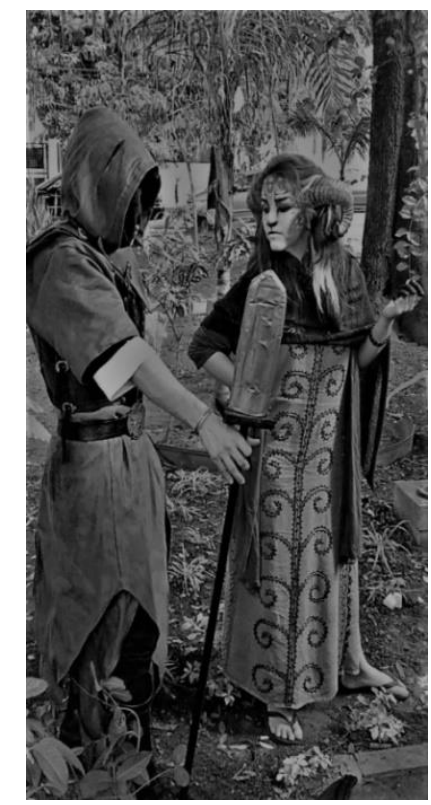

Fonte: Acervo da pesquisa 
Figura 5: Cenas da Peça Medieval
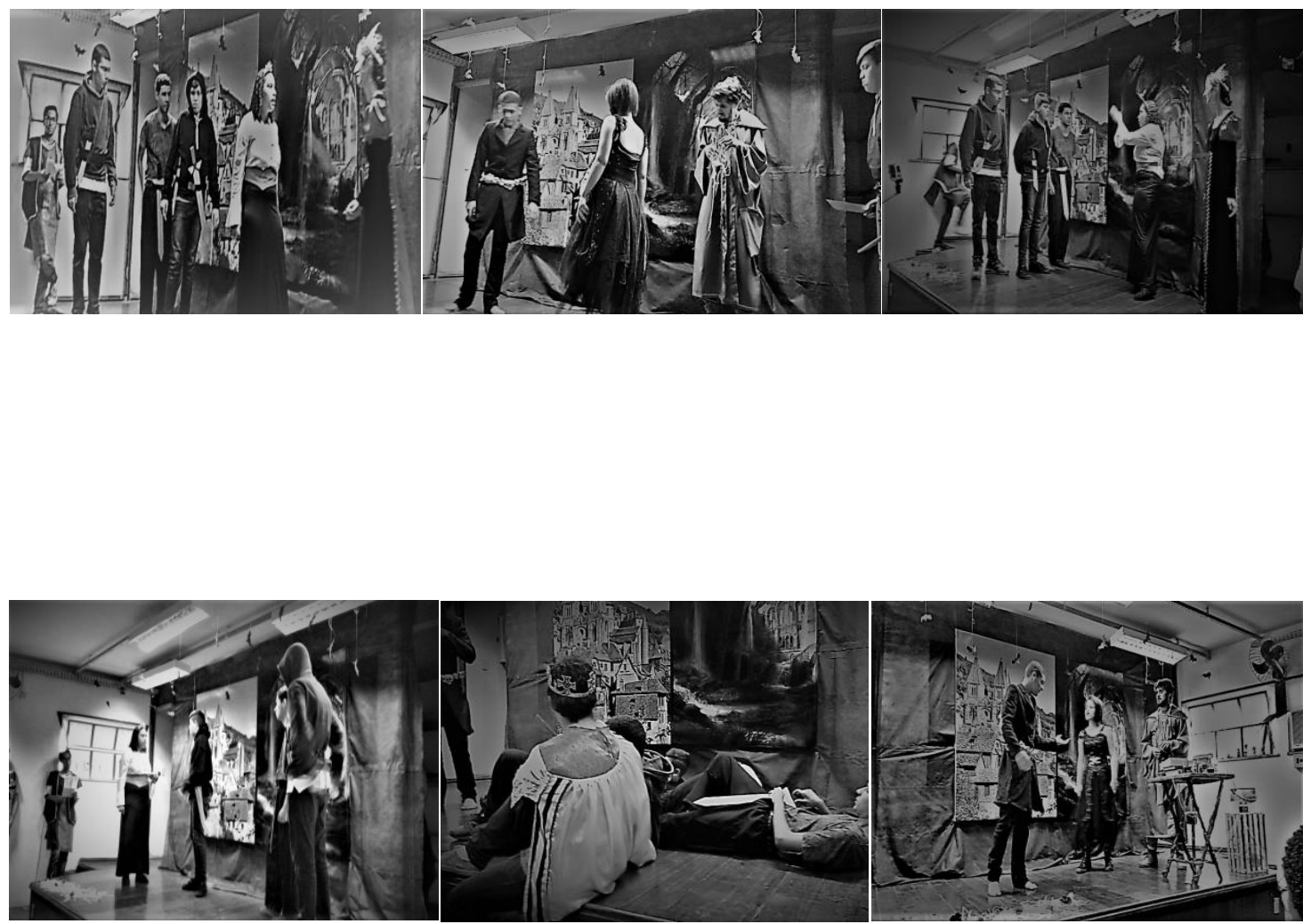

Fonte: Acervo da pesquisa

Figura 6: Agradecimentos

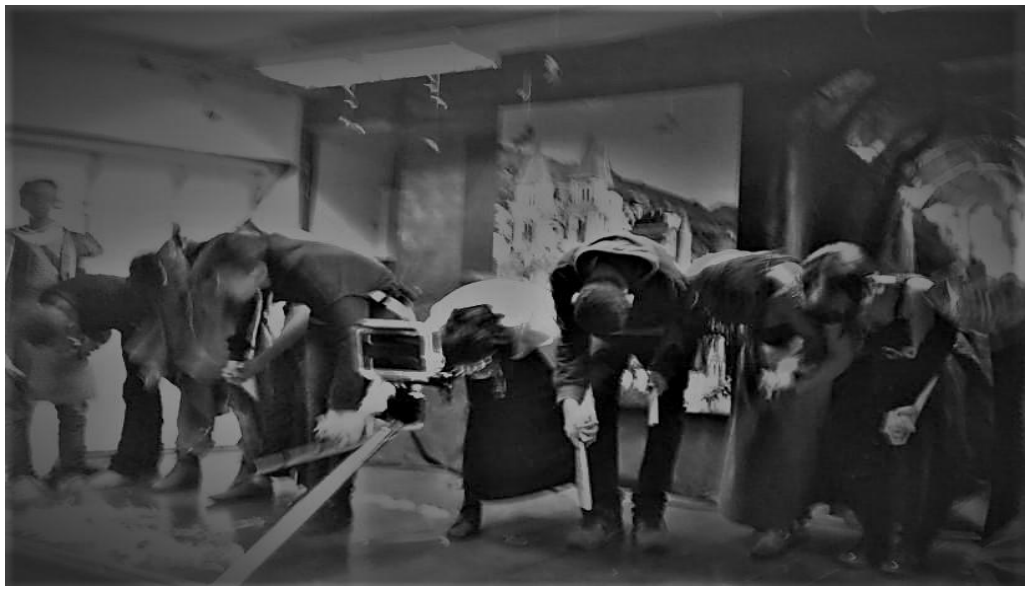

Fonte: Acervo da pesquisa

Revista Interinstitucional Artes de Educar. Rio de Janeiro, V. 7, N.2, p. 1134-1147 mai-ago de 2021: "Dossiê História das Mulheres e Educação" - DOI: 10.12957/riae.2021.63457 


\section{Concluindo...}

Ressignificar o fracasso escolar é pensar na construção de possibilidades a partir das potencias de casa sujeito, é auxiliar a reconstruir identidades e relações de pertencimento. Tudo isso só foi possível por entendermos que educar é trocar afetos e experiências. Afetos - afetar e se deixar afetar, produzir afecções no dizer de Spinoza (2009); compartilhar a vida, trocar saberes e no diálogo produzir novos saberes - saberes de experiências feitos (Freire, 1996); narrar experiências e, tornar-se narrador de sua própria vida (Benjamin, 1985). Narramos nossa experiência e no diálogo Freire, Maturana, Spinoza e Benjamim aprendemos que o caminho para uma educação potente não tem fórmula mágica e nem definida, tem acolhimento, tem a observação aos detalhes, tem o acreditar no outro.

Quando compreendemos que as queixas iniciais são na verdade expressões de opressão de individualidades e pluralidades, e transformamos isso em arte, confirmamos, pela ação, nossa hipótese de que ao fraturar o discurso do fracasso substituindo - pelo conceito de pela Injustiça Cognitiva, engendramos uma pedagogia emancipadora, fundada na diferença e voltada não para a inclusão (pedagogia da hospitalidade hostil), mas para a justiça cognitiva (e social), consubstanciada na máxima dos socialistas utópicos: "de cada um segundo sua capacidade, para cada um segundo sua necessidade". Combater as Injustiças cognitivas no cotidiano escolar é lutar por uma educação e uma sociedade democrática. Entendemos que esta é a tarefa do educador comprometido com a transformação social - SER MAIS, como pessoa, como educador, como cidadão; colocar sua prática a serviço dos oprimidos e possibilitar a cada educando SER MAIS, como pessoa, como cidadão ...

\section{Referências}

BENJAMIM, Walter. O Narrador. In: BENJAMIM, Walter. OBRAS ESCOLHIDAS. Magia e Técnica. Arte e Política. Volume 1. São Paulo: Editora Brasiliense, 1985.

DECLARAÇÃO DE SALAMANCA: Disponível em: portal.mec.gov.br/seesp/arquivos/pdf/salamanca.pdf. Acessado em: 08/02/2016.

FONSECA, Nathália S. B. Injustiças Cognitivas: ressignificando os conceitos de cognição, memória e aprendizagem no cotidiano escolar. Relatório PIBIC. Rio de Janeiro: CNPq, 2016/2017.

FREIRE, Paulo. Pedagogia da Autonomia. São Paulo: Paz e Terra, 1996. 
GARCIA, Vânia B. Identificando talentos adormecidos. In: Mostra de iniciação a docência UFF. Rio de Janeiro: 2017.

MATURANA R., H. Emoções e linguagem na educação e na política. Belo Horizonte: Ed. UFMG, 1998.

PÉREZ, Carmen Lúcia Vidal. Injustiças Cognitivas: ressignificando os conceitos de cognição, memória e aprendizagem no cotidiano escolar. Projeto de Pesquisa. Rio de Janeiro. CNPq, 2016.

SKLIAR, C. Pedagogia (improvável) da diferença: e se o outro não estivesse aí? Rio de Janeiro: DP\&A, 2003.

SPINOZA, B. Ética. Belo Horizonte: Autêntica, 2009.

WERNER, J. Saúde e Educação: desenvolvimento e aprendizado do aluno. Rio de Janeiro: Gryphus, 2000.

\title{
NOTAS
}

\begin{abstract}
' A pesquisa ora em projeto é um desdobramento da investigação que vem sendo desenvolvida desde 2008, pela Prof $^{a}$. Dr ${ }^{a}$. Carmen Lúcia Vidal Pérez, cujo foco é a construção de conhecimentos no processo de apropriação da leitura e da escrita por crianças das classes populares. A pesquisa "Injustiças Cognitivas: ressignificando os conceitos de cognição, memória e aprendizagem no cotidiano escolar" se desenvolve há 08 (oito) anos com crianças de classes populares, alunos do ensino fundamental de escolas públicas de periferias urbanas (entendemos periferia como uma categoria social e não geográfica)
\end{abstract}

ii INTER(in)VENÇAO - Pérez (2007) nos apresenta o termo INTER(in)VENÇÃO, como uma abordagem metodológica de suas investigações. Segundo a autora suas pesquisas realizadas em parceria com as crianças e professoras no cotidiano da escola, mas do que se caracterizarem como intervenções (fundadas na pesquisa ação), se caracterizam como um processo de invenção (no sentido deleuziano do termo) com os todos os envolvidos crianças, professoras, pesquisadoras, professoras em formação inicial, num processo compartilhado que se realização in, ou seja no espaço praticado cotidianamente por todos esses sujeitos. Trata-se de uma pesquisa compartilhada fundada na relação horizontalizada sujeito-sujeito.

iii De acordo com Werner (2000, p.25), na visão mecanicista a criança / adolescente é “portador de alguma deficiência que o impede de reproduzir o comportamento esperado".

iv De acordo com Werner (2000, p.26), na visão organicista os “problemas de aprendizagem (...) passam a ser vistos como decorrentes da imaturidade. A imaturidade, por sua vez, seria consequência da falta de estímulos e experiências que estariam retardando as mudanças nas estruturas psíquicas da criança”.

${ }^{\vee}$ De acordo com Werner (2000, p.27), na visão histórico-social, a criança / adolescente "não será representado nem como máquina (mecanicismo) nem como um mero ser vivo (organicismo), mas como um sujeito social, constituido intrinsecamente por relações sociais, culturais e históricas."

vi Motivos dos encaminhamentos: agitação, agressividade, alteração de humor, apatia, atitudes sexuais, autoagressão, defasagem série/idade, depressão, dificuldade de aprendizagem dificuldade de socialização, dislalia, dislexia, imaturidade, impulsividade, insegurança, insônia, surto alucinatório, transtorno desafiador opositor. 